\title{
Seasonal affective disorder, winter type: current insights and treatment options
}

This article was published in the following Dove Press journal:

Psychology Research and Behavior Management

30 November 2016

Number of times this article has been viewed

\author{
Ybe Meesters' \\ Marijke CM Gordijn ${ }^{2,3}$ \\ 'University Center for Psychiatry, \\ University Medical Center Groningen, \\ 2Department of Chronobiology, \\ GeLifes, University of Groningen, \\ Groningen, the Netherlands; \\ ${ }^{3}$ Chrono@Work B.V., Groningen, \\ the Netherlands
}

\begin{abstract}
Seasonal affective disorder (SAD), winter type, is a seasonal pattern of recurrent major depressive episodes most commonly occurring in autumn or winter and remitting in spring/summer. The syndrome has been well-known for more than three decades, with light treatment being the treatment of first choice. In this paper, an overview is presented of the present insights in SAD. Description of the syndrome, etiology, and treatment options are mentioned. Apart from light treatment, medication and psychotherapy are other treatment options. The predictable, repetitive nature of the syndrome makes it possible to discuss preventive treatment options. Furthermore, critical views on the concept of SAD as a distinct diagnosis are discussed. Keywords: seasonal affective disorder, review, light treatment, medication, psychotherapy, prevention
\end{abstract}

\section{Introduction}

Seasonal affective disorder (SAD), winter type, is an almost yearly recurrent depression with the onset of symptoms in autumn/winter followed by a spontaneous recovery in spring/summer. In their now classical paper, Rosenthal et $\mathrm{al}^{1}$ described the syndrome and presented the first study using light treatment (LT) for SAD. Since then, the syndrome has been described in several editions of the Diagnostic and Statistical Manual of Mental Disorders (DSM) and is still included in the most recent fifth edition (DSM-5). ${ }^{2}$ In this paper, an overview of the syndrome, its prevalence, etiology, assessment procedures, treatment modalities, and some criticisms about the concept of SAD are presented.

\section{The syndrome}

The SAD syndrome, winter type, or winter depression has been described and studied since the early 80 s of the previous century. In the last three editions of the DSM, SAD was either formulated as a specifier of a major depression or as a specifier of a bipolar I or II disorder, but not as an independent entity. Despite the arguments of Rosenthal to formulate SAD as a distinct entity, it is still a specifier in the DSM-5. ${ }^{3}$

Arguments for and against the choice for SAD as a specifier and not a distinct category can be found, and both have consequences for the recognition and treatment.

Classification systems are consensus based, which is not always identical to evidence based. The advantage of inclusion in the classification systems is the recognition of the symptoms, which makes it easier or more acceptable to treat these patients within different health care systems. Therefore, it is important to formulate distinct categories.
Correspondence: Ybe Meesters University Center for Psychiatry, University Medical Center Groningen, PO Box 30 00I, 9700 RB Groningen, the Netherlands

Email y.meesters@umcg.nl 
The disadvantage to formulating the definition of SAD as a specifier of another depressive category, and not as a distinct entity in itself, in classification systems is that SAD becomes less clear and therefore less recognizable for clinicians. That may influence their choice of treatment and keep them from offering the treatment of first choice to their patients.

One argument in favor of an independent diagnosis is that the clinical presentation of the symptoms of SAD differs from that of other depressions and that treatment options also differ. SAD is defined as a distinct syndrome with specific symptoms and a characteristic treatment of first choice. The symptoms occur in autumn/winter and disappear in spring/ summer on an almost yearly basis. SAD sufferers experience some atypical symptoms during wintertime, such as hypersomnia, increased appetite, overeating and weight gain, a preference of carbohydrate food, extreme loss of energy, and loss of social activity. ${ }^{1}$ Women are more often affected by SAD than men (ratio 4:1), ${ }^{4,5}$ and SAD is also more common among younger people. ${ }^{5}$

\section{Prevalence}

Epidemiological studies show that the prevalence of SAD is between $1 \%$ and $10 \%$ of the population and that it seems to be related to latitude. Since a shortage of daylight is involved, it would seem logical that prevalence is higher at more northern latitudes. The influence of latitude is sometimes unclear, though, ${ }^{6}$ but prevalence in North America is two times higher compared to Europe. ${ }^{7}$ A significant correlation between latitude and prevalence was found in North America, but in Europe only a trend in the same direction was found. Studies in some northern European countries have shown more mixed results. ${ }^{6}$

Many of the epidemiological studies mentioned use the Seasonal Pattern Assessment Questionnaire (SPAQ). Using this questionnaire may overestimate the prevalence of SAD. ${ }^{6,8}$

\section{Working mechanism and etiology}

SAD patients - only winter type is considered here - are obviously vulnerable to the effects of the changing seasons and suffer from a lack of (day)light in the winter season. In most cases, LT is effective in these patients. The etiology of SAD and the working mechanism of light are still unknown, however.

A number of different hypotheses have been formulated to unravel etiology and working mechanism, but to date no sufficient evidence has been found in support of these hypotheses. The most prominent hypothesis is that a disturbance of SAD patients' biological clock underlies the complaints. In early days, Lewy et a ${ }^{9-11}$ described their phase-shift hypothesis, which postulates that the biological clock is out of phase (mostly delayed) with the natural daynight cycle. In a minority of patients, the circadian system is phase advanced. Lewy et al $1^{9,10,12}$ assumed that LT in the morning would cause a phase correction and therefore be beneficial to SAD sufferers. Several studies have confirmed LT in the morning to be superior to LT at other times of the day, ${ }^{13}$ but other studies have shown the effectiveness of LT in the evening or at midday, ${ }^{14-16}$ and have confirmed a positive treatment effect without inducing phase shifts in the circadian system. ${ }^{17,18}$ Since no study is available to show that evening LT is superior to morning LT, only that it is equally effective, and studies showing that morning light is superior do in fact exist, it became clinical practice to offer LT in the morning. More recently, Lewy et a ${ }^{19}$ refined their phase shift hypothesis and showed support for the assumption that an internal desynchronization between rhythms driven by the biological clock and the sleep-wake rhythm are causal in the pathology of SAD, and they also support morning light therapy as the most effective treatment.

The exact timing of LT in the morning for the treatment to be optimally effective may differ between chronotypes. Chronotype refers to the actual timing of sleeping and activity in individuals, which results in a broad distribution of different groups ranging from extreme evening-types to extreme morning-types, with intermediate types in the middle. Evening-type individuals in particular are seen to have a higher risk of getting depressed. ${ }^{20}$ Chronotypes in the SAD population differ in their baseline phase of melatonin onset (as a marker of the timing of their circadian clock) by up to 5-6 hours. Terman et $\mathrm{a}^{21}$ showed that due to differences in the timing of light, smaller or larger phase shifts of melatonin were found, with larger responses accompanying a larger phase advance of melatonin onset. Assessing melatonin onset, however, is not always feasible. The scores of the Morningness Eveningness Questionnaire ${ }^{22}$ have been shown to highly correlate with melatonin onset, making it a practical tool in the assessment of the optimal LT time. ${ }^{21,23}$ Contrary to these studies, Knapen et $\mathrm{al}^{24}$ show in a retrospective study that exposure at a fixed time in the morning does not show different treatment outcomes for SAD patients with different Morningness Eveningness Questionnaire sores, although these outcomes were not necessarily the most optimal response.

Light exposure has to be at the level of the retina to affect the circadian system, as assessed by means of a shift in dim light melatonin onset. A small study of Wehr et $\mathrm{al}^{25}$ on 
SAD treatments showed a superior effect of light exposure through the eyes compared to exposure to the skin. Based on behavioral similarities in plants and animals, Oren ${ }^{26}$ proposed another way of photo transduction than through the eyes only. He supposed that the signal of light could be transported to the brain through the hemoglobin in the red blood cells. In this line of reasoning, it is thought to be possible to influence the human circadian system in healthy people by administering light at the back of the knees (where large blood vessels are present near the surface). ${ }^{27} \mathrm{~A}$ logical next step was to investigate the antidepressant effects of light at the back of the knees in SAD patients. The effects of light at the back of SAD sufferers' knees were comparable to those of a placebo condition. ${ }^{28}$ Also, in a replication of the first study claiming some positive results on circadian rhythms from light exposure to the back of the knees, and several other studies, no support for these finding was found..$^{29,30}$ This does not mean that we are absolutely certain that the positive results of antidepressant LT can only be reached by means of exposure to the eyes. In a recent paper, Oren et $\mathrm{al}^{31}$ described an evolutionarybased theoretical model of humoral phototransduction and the possible roles of hemoglobin and bilirubin in addition to the role of rods, cones, and melanopsin. In a study from Finland, positive results were described after exposure to light through the ears. ${ }^{32}$ This study can be criticized owing to the lack of a real placebo condition, however. Two studies showed that light therapy through the ears did not suppress melatonin production, whereas light exposure at the retina did. ${ }^{33,34}$ Recently, it was shown that passing light through the ears was not effective in shifting the sleep-wake rhythms. ${ }^{35}$ In a study comparing the prevalence of SAD in severely visually impaired subjects $(n=4,099)$ to subjects with full eyesight $(n=2,781)$, it was found that the prevalence of SAD in the former group was significantly higher. The authors argue that these results support the hypothesis that decreased retinal light input plays a role in the pathogenesis of SAD. ${ }^{36}$

Although the study of the effects of transcranial light on depressive symptoms has been criticized for its lack of a placebo condition, the real problem in clinical studies on the effects of ocular LT is that it is impossible to create a methodologically justified placebo condition (or LT without the supposed effective part without the participant noticing this).

In light research, various placebo-like conditions have been used, such as imaginary light, ${ }^{37}$ invisible light, ${ }^{38}$ extraocular light, ${ }^{28}$ low-intensity light,${ }^{39}$ or another placebo condition totally unrelated to light, such as a deactivated ion generator. ${ }^{40}$ Responses to these "placebo" conditions have been found to vary from $36 \%$ to $46 \%$.
There are nonetheless some promising developments in the search for convincing evidence in the diagnosis and etiology of SAD.

Hypocretin/orexin neuropeptides (hcrt) play a role in controlling patterns of sleep and wakefulness. In a Danish study on 227 subjects suffering from hypersomnia, a seasonal variation in hcrt was found in cerebrospinal fluid, correlating with day length. This finding might be helpful in the understanding of a physiological basis for fatigue in wintertime or SAD. ${ }^{41}$ The preliminary conclusion of a small study on SAD patients is that it is possible to find useful biomarkers with gene expression in white blood cells. ${ }^{42}$ Another recent progress in the search for biomarkers was the identification of a serotonin transporter binding with a potential role in LT of $\mathrm{SAD}^{43}$ and higher levels of serotonin transporter binding in the whole brain, but specifically in areas involved in the regulation of affect in SAD. ${ }^{44,45}$ In the longitudinal study by Mc Mahon et al ${ }^{45}$ the seasonal change in serotonin transporter binding was observed to be positively associated with the change in depressive symptom severity, suggesting that the development of depressive symptoms in winter is associated with a failure to downregulate serotonin transporter levels, a phenomenon observed in healthy controls. Finally, a recent paper focused on a possible relationship between the immune system and SAD. Song et $\mathrm{al}^{46}$ found that SAD patients have enhanced inflammatory responses in winter in their depressed state compared to healthy controls. Light therapy improved mood and normalized their immune function.

\section{Assessment}

A clinical interview using a structured and standardized questionnaire is often been seen as the gold standard to diagnose a psychiatric disorder or to rate symptom severity. In depression research, the Hamilton Rating Scale for Depression (HRSD) ${ }^{47}$ has often been used from 1960 onward for this purpose. The need arose to improve the interrater reliability of this clinical interview. This led to the development of structured interview guides. In addition, there was a clear need to rate the atypical symptoms. ${ }^{48}$ These two aspects were combined in the Structured Interview Guide for the Hamilton Depression Rating Scale - Seasonal Affective Disorder version (SIGH-SAD). ${ }^{49}$ Rohan et a $l^{50}$ have recently presented a protocol and rules for the scoring of the HRSD and have reported high interrater reliability scores. A selfrating version of the SIGH-SAD rating scale is also available. The latest version of this instrument has a slightly different title, since atypical symptoms are not exclusive for SAD: Structured Interview Guide for the Hamilton Depression 
Rating Scale with Atypical Depression Supplement (SIGHADS). ${ }^{51}$ The HRSD, SIGH-SAD, and SIGH-ADS assess the severity of the depression but are unsuitable for use as a diagnostic instrument. Instruments to diagnose depression are the Structured Clinical Interview for DSM-IV axis I disorders (SCID-I) ${ }^{52}$ or the Mini-International Neuropsychiatric Interview (M.I.N.I.). ${ }^{53}$

The severity of a depression with a clinical diagnosis can vary from mild to very severe. The severity of depression can be assessed by means of self-ratings, but in more severe depressions, a standardized structured clinical interview would certainly be preferable.

The SPAQ is popular as a screening instrument and is often used in epidemiological studies. ${ }^{54}$ This self-rating instrument consists of seven sections on seasonal changes in some key variables. A subscale assessing seasonal changes in mood, energy, social activity, sleep, weight gain, and eating habits is particularly suited to calculate a so-called Global Seasonality Score (GSS). The existence of seasonal complaints, their severity, and a certain global seasonality score enable this instrument used in epidemiological studies to estimate SAD prevalence. Although the SPAQ is widely used, its validity has been criticized. ${ }^{55-60} \mathrm{~A}$ number of new self-rating instruments have been developed for the assessment of seasonal depression, such as the Seasonal Health Questionnaire (SHQ) ${ }^{61}$ or more recently, the Seasonality Assessment Form. ${ }^{62}$ The SHQ would seem to be more sensitive and specific in assessing seasonal depression than the SPAQ and be of more predictive value as a screening instrument. ${ }^{63}$ Prevalence estimates for SAD when using the SHQ are lower than when using the SPAQ. ${ }^{63,64}$ A high score on the SPAQ or other self-rating instruments is not identical to a SAD diagnosis, however. Direct structured interviewing remains superior. ${ }^{8}$

\section{Light treatment}

In a paper by Lewy et al, ${ }^{65}$ the first detailed description of exposure to bright white light in the treatment of SAD was published in a case study. They reported a successful treatment of a single patient with exposure to bright light, lengthening the day light period. Rosenthal et $\mathrm{al}^{1}$ published the first study in which exposure to bright light was successful in treating SAD. Ever since, a large amount of studies have been published in which the effect of LT as an antidepressant therapy has been shown. Nowadays, LT is the treatment of first choice for SAD sufferers. ${ }^{23,66-70}$ Most studies investigate the effects of LT in adults, but in a number of small studies and case studies positive results after LT in children and adolescents have also been described. ${ }^{71-74}$
In the early days, it was common to use bright white light with an intensity of 2,500 lux for 3 hours; nowadays, LT with bright light intensity of 10,000 lux for 30-45 minutes per session has become more or less the standard..$^{23,56,75}$ In the first studies, effects were reported after 3 days of light exposure. Later on, the duration of the LT was lengthened. The effects of 2 weeks of LT were reported to be superior to those of 1 week, ${ }^{76}$ but it was questioned whether this effect after the second week of LT was actually caused by the exposure to light. Meesters ${ }^{77}$ described that the effects of LT as assessed 1 week after finishing exposure to light were superior to the results immediately after ending the 1 -week treatment.

The duration of the treatment offered does in fact affect the response to the treatment. Levitt and Levitan showed that a shorter duration of LT ( 2 weeks) can be equally effective as a longer duration ( 5 weeks). ${ }^{78}$ This suggests that the response rate in the group receiving shorter LT duration is faster. A retrospective study comparing the therapeutic effects between studies with 1 vs 2 weeks of LT arrived at the same conclusion. ${ }^{79}$

Because of the potential role of the circadian system in the pathology of SAD and the observed effects of LT, the discovery of a novel photoreceptor, the retinal ganglion cells containing melanopsin, has heavily influenced the field. ${ }^{80-84}$ These non-image forming photoreceptors influence the circadian system and are most sensitive to light with a wavelength of 470-490 nm (blue light)..$^{85}$ On the basis of these findings, several studies have been conducted studying the possible role of the melanopsin cell in the LT effects of SAD. Based on this knowledge, blue or blue-enriched light fixtures have become available for the treatment of SAD patients. In a study where extra blue light was added to the fixtures $(17,000 \mathrm{~K})$, the therapeutic outcome was compared to the conventional treatment outcome with bright white light. No differences were found between 30 minutes of conventional bright light exposure compared to 30 or 20 minutes of exposure to blueenriched bright light; in all conditions, high responses were found. ${ }^{86}$ Because of possible saturation effects, the study was repeated with low-intensity (750 lux) blue-enriched light compared to bright white light, with no differences in treatment outcome. ${ }^{39}$

With the invention of blue-light-emitting diodes (LEDs), narrow-band light sources fitting the maximum sensitivity of the NIF photoreceptors became available. These fixtures were also used in several studies. The therapeutic outcomes of exposure to blue light were found to be superior to those of red light; ${ }^{87,88}$ blue-enriched LED light was superior to placebo, ${ }^{40}$ but similar to blue light. ${ }^{89}$ In studies comparing the therapeutic outcomes after exposure to low-intensity 
narrow-band blue light with that of bright white light, no differences were found in the treatment effects in $\mathrm{SAD}^{90}$ or subsyndromal SAD (winter blues). ${ }^{60}$ In a recent study comparing the therapeutic results after exposure to blue light ( $\sim 65 \mathrm{~nm})$ vs exposure to blue-free light (595-612 nm) no difference in treatment outcome was found. ${ }^{91}$ If this latter study can be replicated with a larger sample size, the role of the blue light as an essential ingredient of successful LT should be questioned.

In addition to fixed light equipment, portable light fixtures have become available, such as head-mounted devices (light visors), ${ }^{92}$ and since the introduction of LEDs other portable devices. ${ }^{40,60}$ The commonality among all these light therapies is that patients are awake and exposed to light at the retina by sitting in front of a light fixture or via a head-mounted light device. Another way of LT is the use of dawn simulation. In the wintertime, a gradual increase of morning light is simulated just prior to wake-up time (mostly from 0 to 300 lux in 30 minutes). Positive results have been reported. ${ }^{93,94}$ An advantage of dawn simulation is that it is less time-consuming than more traditional LT. People receive the light when they are still sleeping until they wake up. Patients who are less motivated to spend time in front of a light fixture can reap the benefits of LT this way. ${ }^{95}$ Dawn simulation has also been shown to have positive effects on waking up, reducing sleep inertia in healthy subjects, without shifting the biological clock. ${ }^{96,97}$ When comparing the therapeutic results of bright light vs dawn simulation, the results of exposure to bright light have been better. ${ }^{98,99}$ In a study with exclusively hypersomnic SAD patients, exposure to dawn simulation was shown to be superior to exposure to bright white light. ${ }^{100}$

Although LT is highly effective, it sometimes has side effects or contraindications. Regularly reported side effects are mild visual complaints, nausea, dizziness and headaches, tired eyes, agitation, sleep disturbances, or, very rarely, (hypo) manic decompensation. ${ }^{23,101,102}$ (Relative) contraindications are preexisting retinal diseases, the use of photosensitizing drugs, and recent eye surgery. ${ }^{23}$ If there is any doubt about eye health, it is recommended people consult an ophthalmologist before starting LT. Although detrimental effects on eye health caused by LT are rarely reported, some eye specialists warn against the effects of high-intensity light on the eyes, ${ }^{103}$ against the effects of narrow-band blue light in particular. ${ }^{104}$

\section{Medication}

The number of studies on antidepressant medication in the treatment of SAD is not very high. In a placebo-controlled study, the effects of fluoxetine did not differ from that of the placebo treatment, both were equally effective. ${ }^{105}$ In a placebo-controlled study, Ruhrmann et al ${ }^{106}$ found no difference in treatment outcome between the use of LT compared to fluoxetine, with remission rate after LT tending to be superior.

In a large placebo-controlled study $(n=187)$, it was shown that sertraline was superior to placebo and was well tolerated in the treatment of SAD. ${ }^{107}$ In a comparison between LT, fluoxetine, and placebo, Lam et $\mathrm{al}^{108}$ found that at the end of the treatment both light and medication had been effective, with LT having an earlier onset of recovery and fewer adverse effects than fluoxetine $(n=96)$. These two studies are the largest ones investigating the effects of medication in the treatment of SAD. In a meta-analysis of the effects of second-generation antidepressants, only three studies fulfilled the inclusion criteria, all using fluoxetine as medication; little evidence for a treatment effect based on this small number of trials is presented. ${ }^{109}$

There are several very small studies or open-label studies claiming some positive effects of other antidepressants. ${ }^{110}$ One of these open-label studies is by Pjerk et $\mathrm{al}^{111}$ who reported positive effects of the use of agomelatine $(n=37)$, but to our knowledge no controlled studies supporting this conclusion have been published yet. Partonen and Lönnqvist $^{112}$ found that the use of moclobemide was equally effective compared to the use of fluoxetine in treating SAD $(n=32)$, but no placebo-control condition was available. In a larger study $(n=282)$, it was found that after one successful week of LT, the use of citalopram was more effective at preventing a relapse during the next 15 weeks than placebo. ${ }^{113}$ The effect of bupropion has not been investigated very thoroughly in treating the acute phase of SAD. ${ }^{114}$ Since it has a positive effect in the prevention of $\mathrm{SAD}$, bupropion is the only licensed drug used in the treatment of SAD.

\section{Psychotherapy (CBT)}

Psychotherapy, which is successful in nonseasonal depression, might prove to be useful in treating SAD as well. There is some support that SAD can be explained by underlying dysfunctional attitudes. ${ }^{115}$ Since 2007 , Rohan et $\mathrm{al}^{116}$ have described positive results of Cognitive Behavioral Therapy (CBT) by itself or in combination with LT. Six weeks of CBT with two 90-minute sessions per week were equally effective as LT for 30 minutes every morning. ${ }^{117}$ In an exploratory study, Sitkinov et $\mathrm{al}^{118}$ found that SAD patients with more cognitive problems at baseline had more complaints in the next winter if they were offered LT as a monotherapy compared to those who received CBT or CBT combined with LT. 
Depending on a correct baseline diagnosis, these findings may play a role in the choice of first treatment.

\section{Other treatments}

Besides LT, medication, and psychotherapy, other treatments are sometimes offered to SAD sufferers. From the herbal therapies, only some evidence for a therapeutic effect is described after the use of St. John's Wort (Hypericum perforatum), ${ }^{119-121}$ but not for Kava (Piper methysticum). ${ }^{121}$ Neither has any difference been found between the use of Ginko biloba extract and placebo in the prevention of SAD symptoms. ${ }^{122}$

There is some weak evidence that the use of tryptophan has some benefits in the treatment of $\mathrm{SAD}^{123,124}$ and probably also in those responding poorly or not at all to LT. ${ }^{125}$

Physical exercise, either by itself, or in combination with LT, has also been shown to have a positive effect on mood in SAD patients. ${ }^{126,127}$

\section{Prevention}

Since winter depression is by definition a recurrent disease, efforts have been made to find treatment options for the prevention of the next full-blown depressive episode. Preventive treatment options are based on exposure to light, medication, and CBT.

In one study, it was shown that LT offered at the first signs of the depressive episode prevented the development of a full-blown depressive episode in the remaining part of the season. ${ }^{128}$ In a more or less replication study, it was shown that LT offered at the first signs of the episode could postpone the development of the next episode. ${ }^{129}$ Offering LT at the start of the autumn, when no complaints of depressive symptoms were present, did not prevent a depressive episode in the following winter period. ${ }^{130}$

Starting with LT before SAD patients show symptoms and continuing this treatment into the period in which patients were having complaints in former winters may lead to the prevention or early treatment of a depressive episode. ${ }^{131}$

The use of light visors (wearable light fixtures on the head) during the winter made it possible to prevent a depressive episode..$^{92}$ This last study was the only one to fulfill the criteria of a Cochrane review about the possibilities of LT in preventing the development of a depressive episode in SAD patients, ${ }^{132}$ and so the evidence to use LT as a preventive method has to be investigated further in order to find more support for this treatment modality.

In a large study, $n=1,042$, the use of bupropion in preventing the recurrence of SAD symptoms was investigated. ${ }^{133}$ These authors showed that the use of bupropion, started before the depressive episode in wintertime, was superior to placebo in preventing a depressive episode in the following winter. In a review about the use of bupropion in treating SAD, based on the results of previous studies and some open-label studies showing that the use of this medication had some effect, the authors concluded that the use of bupropion is a treatment option well-tolerated by patients, but they also stated that for a definitive conclusion more placebo-controlled studies are needed. ${ }^{114}$ In a Cochrane review regarding the use of secondgeneration antidepressants to prevent SAD, only the Modell et $\mathrm{al}^{133}$ studies were accepted for inclusion. Their conclusion was that bupropion is effective in the prevention of SAD, but they cautioned that these effects are not large, since 4 out of 5 patients did not benefit at all and a next depressive episode was not prevented. Because of the side effects of bupropion, the authors suggest that this treatment option be carefully discussed with patients, considering the advantages, disadvantages, and other potentially effective interventions. ${ }^{134}$

No controlled studies of the use of melatonin or agomelatine in the prevention of SAD are available. ${ }^{135}$

In a Cochrane review on psychological therapies for the prevention of SAD, no studies fulfilled the inclusion criteria. ${ }^{136}$ After publication of this review, a study of Rohan et $\mathrm{al}^{137}$ was published which reported that the effects of CBT were superior to LT for two consecutive winters after acute treatment. This suggests that CBT has greater durability in treating SAD and leads to less relapse compared to LT.

There is some evidence in the literature that Mindfulness Based Cognitive Therapy (MBCT) is useful in the prevention of depressive episodes in recurrent depressions when patients are in remission. ${ }^{138} \mathrm{As} \mathrm{SAD}$ is a recurrent depression, it makes sense to offer MBCT to SAD patients in summer, when their depression is in remission. A small pilot study, however, concluded that MBCT was of no use in preventing a depressive episode in wintertime. ${ }^{139}$

\section{Criticisms}

Although there is a large amount of literature on SAD, and the positive results of light therapy and other treatments have been carefully described, some papers criticize the concept of SAD and the working mechanisms of LT. Stuhlmiller, ${ }^{140}$ for example, stated that the effects of the seasons on psychological changes are inconsistent, controversial, and influenced by the appreciation of cultural perception and adaptation. More recently, Traffanstedt et al ${ }^{141}$ have described the results of a cross-sectional survey using the Patient Health Questionnaire-8 Depression Scale. Their results do not support the construct of a seasonal modifier in major depression, and 
so the authors suggest discontinuing seasonal variation as a diagnostic modifier of depression. They question the validity of the commonly used SPAQ because of its retrospective character (assessing complaints over at least 1 year) and the fact that the SPAQ does not assess the DSM criteria. Unfortunately, this study does not assess SAD itself, but the higher and lower prevalence of complaints of depression in a crosssectional approach. In a cross-sectional cohort study, using the Kessler Psychological Distress Scale (K10), Winthorst et al ${ }^{142}$ did not find a clear seasonal pattern in predefined depressive subgroups. Using the SPAQ in the same population, some seasonal variation was found in subgroups with depression and anxiety. ${ }^{143}$ These two studies show that if the survey contains no specific relevant questions that relate to the concept of seasonal variations, no relevant answers can be found.

Considering the concept of the effects of light therapy in $\mathrm{SAD}$, Martensson et al ${ }^{144}$ reported the results of a metaanalysis using very strict inclusion criteria. They found an effect size of 0.54 for the effect of bright white LT in SAD and criticized the results of the meta-analysis of Golden et $\mathrm{al}^{68}$ who reported a larger effect size $(0.84)$ because of their inclusion criteria. Martensson et al ${ }^{144}$ concluded that the evidence for the clinical use of bright white LT for SAD is weak at most. The differences between these two studies clearly show the weaknesses of meta-analyses: results can be heavily influenced because of the a priori formulated inclusion criteria. The problem with small studies is that their power is limited due to small sample sizes. Meta analyses have more power, but can be biased because of the a priori selection of criteria for inclusion or exclusion of studies. Epidemiological studies are mostly based on surveys or questionnaires and do not cover an actual diagnosis. A clinical diagnosis using an interview may clearly differ from the results of a survey based on questionnaires. ${ }^{8}$

As discussed earlier, it is still impossible to create a methodologically justified placebo condition to compare with the effects of LT. Theoretically, it remains possible that the effects of LT can be explained by a specific therapeutic variable unrelated to the light, such as an improvement of day-night structure, recognition of the complaints by a professional, or to placebo. Such variables definitely play a role, but it would seem unlikely that the quick and robust effects of LT can have existed for decades without having any intrinsic effects.

\section{Conclusion}

For more than three decades now, both for clinicians and researchers, SAD has been a source of inspiration in the discussion of the etiology and mechanisms underlying the treatment effect. For many years, a large number of SAD sufferers have benefited from the exposure to artificial bright light, which has become the treatment of first choice. Positive results have also been reported after the use of antidepressant medication, such as SSRIs and bupropion. The success of different treatment methods can be explained by means of the dual vulnerability model. ${ }^{145-147}$ This model proposes that SAD patients are vulnerable to developing severe vegetative symptoms (eg, sleep, appetite, energy) and also have an additional vulnerability to develop psychological symptoms.

The knowledge about the etiology of SAD and the working mechanisms of LT is still growing, but not decisively. Some treatments are based on theories, but not all of the reported therapeutic outcomes can be explained by means of these theories. This does not mean that these theories or treatments are useless. Inconclusive results can be an inspiration for further research. The way the syndrome is diagnosed can be improved, as can the assessment, theories, and treatment procedures. This is by no means a negative conclusion degrading the concept of SAD and light therapy, since no diagnosis or treatment in the field of mental health, has perhaps shown such large improvements over a period of about 30 years. It is a stimulant to go on.

\section{Acknowledgment}

The authors are grateful to Josie Borger for the improvement of the English.

\section{Disclosure}

The authors report no conflicts of interest in this work.

\section{References}

1. Rosenthal NE, Sack DA, Gillin JC, et al. Seasonal affective disorder. A description of the syndrome and preliminary findings with light therapy. Arch Gen Psychiatry. 1984;41:72-80.

2. American Psychiatric Association. Diagnostic and Statistical Manual of Mental Disorders. 5th ed. Arlington, VA: American Psychiatric Association; 2013.

3. Rosenthal NE. Issues for DSM-V: seasonal affective disorder and seasonality. Am J Psychiatry. 2009;166:852-853.

4. Mersch PP, Middendorp HM, Bouhuys AL, Beersma DG, Van den Hoofdakker RH. The prevalence of seasonal affective disorder in the Netherlands: a prospective and retrospective study of seasonal mood variation in the general population. Biol Psychiatry. 1999;45:1013-1022.

5. Magnusson A. An overview of epidemiological studies on seasonal affective disorder. Acta Psychiatr Scand. 2000;101:176-184.

6. Magnusson A, Partonen T. Prevalence. In: Partonen T, Pandi-Perumal SR, editors. Seasonal Affective Disorder. Practice and Research. 2nd ed. New York, NY: Oxford University Press; 2010:221-234.

7. Mersch PP, Middendorp HM, Bouhuys AL, Beersma DG, van den Hoofdakker RH. Seasonal affective disorder and latitude: a review of the literature. J Affect Disord. 1999;53:35-48.

8. Levitt AJ, Boyle M, Joffe RT. Lattitude and the variation in seasonal depression and seasonality of depressive symptoms. Soc Light Treat Biol Rhythms. 1997; Abstract 9:14. 
9. Lewy AJ, Sack RL, Miller LS, Hoban TM. Antidepressant and circadian phase-shifting effects of light. Science. 1987;235:352-354.

10. Lewy AJ, Sack RL, Singer CM, White DM. The phase shift hypothesis for bright light's therapeutic mechanism of action: theoretical considerations and experimental evidence. Psychopharmacol Bull. 1987;23:349-353.

11. Lewy AJ, Sack RL, Singer CM, White DM, Hoban TM. Winter depression and the phase shift hypothesis for bright light's therapeutic effect: history, theory, and therapeutic evidence. J Biol Rhythms. 1988;3:121-134.

12. Lewy AJ, Bauer VK, Cutler NL, et al. Morning vs evening light treatment of patients with winter depression. Arch Gen Psychiatry. 1988;55:890-896.

13. Sack RL, Lewy AJ, White DM, Singer CM, Fireman MJ, Vandiver R. Morning vs evening light treatment for winter depression: evidence that the therapeutic effects of light are mediated by circadian phase shifts. Arch Gen Psychiatry. 1990;47:343-351.

14. Hellekson CJ, Kline JA, Rosenthal NE. Phototherapy for seasonal affective disorder in Alaska. Am J Psychiatry. 1986;143:1035-1037.

15. Meesters Y, Jansen JH, Lambers PA, Bouhuys AL, Van den Hoofdakker RH. Morning and evening light treatment of seasonal affective disorder: response, relapse and prediction. J Affect Disord. 1993;28:165-177.

16. Meesters Y, Jansen JH, Beersma DG, Bouhuys AL, Van den Hoofdakker RH. Light therapy for seasonal affective disorder: the effects of timing. Br J Psychiatry. 1995;166:607-612.

17. Koorengevel KM, Beersma DG, Den Boer JA, Van den Hoofdakker RH. A forced desynchrony study of circadian pacemaker characteristics in seasonal affective disorder. J Biol Rhythms. 2002;17:463-475.

18. Wirz-Justice A, Graw P, Krauchi K, et al. Light therapy in seasonal affective disorder is independent of time of day or circadian phase. Arch Gen Psychiatry. 1993;50:929-937.

19. Lewy AJ, Lefler BJ, Emens JS, Bauer VK. The circadian basis of winter depression. Proc Natl Acad Sci U S A. 2006;103:7414-7419.

20. Antypa N, Vogelzangs N, Meesters Y, Schoevers R, Penninx BW. Chronotype associations with depression and anxiety disorders in a large cohort study. Depress Anxiety. 2016;33:75-83.

21. Terman JS, Terman M, Lo ES, Cooper TB. Circadian time of morning light administration and therapeutic response in winter depression. Arch Gen Psychiatry. 2001;58:69-75.

22. Horne JA, Ostberg O. A self-assessment questionnaire to determine morningness-eveningness in human circadian rhythms. Int J Chronobiol. 1976;4:97-100.

23. Wirz-Justice A, Benedetti F, Terman M. Chronotherapeutics for Affective Disorders. A Clinician's Manual for Light and Wake Therapy. 2nd revised version. Basel, Switzerland: Karger; 2013.

24. Knapen SE, Gordijn MC, Meesters Y. The relation between chronotype and treatment outcome with light therapy on a fixed time schedule. $J$ Affect Disord. 2016;202:87-90.

25. Wehr TA, Skwerer RG, Jacobsen FM, Sack DA, Rosenthal NE. Eye versus skin phototherapy of seasonal affective disorder. Am J Psychiatry. 1987;144:753-757.

26. Oren DA. Humoral phototransduction: blood is a messenger. Neuroscientist. 1996;2:207-210.

27. Campbell SS, Murphy PJ. Extraocular circadian photo- transduction in humans. Science. 1998;279:396-399.

28. Koorengevel KM, Gordijn MC, Beersma DG, et al. Extraocular light therapy in winter depression. A double-blind placebo-controlled study. Biol Psychiatry. 2001;50:691-698.

29. Eastman CI, Martin SK, Hebert M. Failure of extraocular light to facilitate circadian rhythm reentrainment in humans. Chronobiol Int, 2000;17:807-826.

30. Wright KP, Czeisler CA. Absence of circadian phase resetting in response to bright light behind the knees. Science. 2002;297:571.

31. Oren DA, Koziorowski M, Desan PH. SAD and the not-so-single photoreceptors. Am J Psychiatry. 2013;170:1403-1412.
32. Jurvelin H, Takala T, Nissilä J, et al. Transcranial bright light treatment via the ear canals in seasonal affective disorder: a randomized, double-blind dose-response study. BMC Psychiatry. 2014;14:288.

33. Bromundt V, Frey S, Odermatt J, Cajochen C. Extraocular light via the ear canal does not acutely affect human circadian physiology, alertness and psychomotor vigilance performance. Chronobiol Int. 2014;31:343-348.

34. Jurvelin H, Takala T, Heberg L, et al. Transcranial bright light exposure via ear canals does not suppress nocturnal melatonin in healthy adults -a single-blind, sham-controlled, crossover trial. Chrononbiol Int. 2014;31:855-860.

35. Pallesen S, Nødtvedt Ø, Saxvig IW, Bjorvatn B. A new light source (Valkee $\odot$ ) does not alter sleep-wake parameters and does not improve mood in phase delayed subjects. Sleep Biol Rhythms. 2016;14:97-105.

36. Madsen HØ, Dam H, Hageman I. High prevalence of seasonal affective disorder among persons with severe visual impairment. $\mathrm{Br} J$ Psychiatry. 2016;208:56-61.

37. Richter P, Bouhuys AL, Van den Hoofdakker RH, et al. Imaginary versus real light for winter depression. Biol Psychiatry. 1992;31:534-536.

38. Meesters Y, Van Os TWDP, Grondsma K, Veneman F, Beersma DGM, Boujuys AL. Light box vs light visor; Bright white vs infrared or placebo light. Soc Light Treat Biol Rhythms. 1997; Abstract 9:27.

39. Meesters Y, Dekker V, Schlangen LJ, Bos EH, Ruiter MJ. Low-intensity blue-enriched white light (750 lux) and standard bright light (10,000 lux) are equally effective in the treatment of SAD. A randomized controlled study. BMC Psychiatry. 2011;11:17.

40. Desan PH, Weinstein AJ, Michalak EE, et al. A controlled trial of the Litebook light-emitting diode (LED) light therapy device for treatment of seasonal Affective disorder (SAD). BMC Psychiatry. 2007;7:38.

41. Boddum K, Hansen MH, Jennum PJ, Komum BR. Cerebrospinal fluid hypocretin-1 (Orexin-A) level fluctuates with season and correlates with day length. PLoS One. 2016;11(3):e0151288.

42. Bosker FJ, Terpstra P, Gladkevich AV, et al. Changes in winter depression phenotype correlate with white blood cell gene expression profiles: a combined metagene and gene ontology approach. Prog Neuropsychopharmacol Biol Psychiatry. 2015;58:8-14.

43. Harrison SJ, Tyrer AE, Levitan RD, et al. Light therapy and serotonin transporter binding in the anterior cingulate and prefrontal cortex. Acta Psychiatr Scand. 2015;132:379-388.

44. Tyrer AE, Levitan RD, Houle S, Wilson AA, Nobrega JN, Meyer JH. Increased seasonal variation in serotonin transporter binding in seasonal affective disorder. Neuropsychopharmacology. 2016;41(10): 2447-2454.

45. Mc Mahon B, Andersen SB, Madsen MK, et al. Seasonal difference in brain serotonin transporter binding predicts symptom severity in patients with seasonal affective disorder. Brain. 2016;139:1605-1614.

46. Song C, Luchtman D, Kang Z, et al. Enhanced inflammatory and T-helper-1 type responses but suppressed lymphocyte proliferation in patients with seasonal affective disorder and treated by light therapy. J Affect Disord. 2015;185:90-96.

47. Hamilton M. Development of a rating scale for primary depressive illness. Br J Soc Clin Psychol. 1967;6:278-296.

48. Rosenthal NE, Heffernan MM. Bulimia, carbohydrate craving, and depression: a central connection? In: Wurtman RJ, Wurtman JJ, editors. Nutrition and the Brain, vol. 7. New York, NY: Raven Press; 1986:139-166.

49. Williams JBW, Link MJ, Rosenthal NE, Amira L, Terman M. Structured Interview Guide for the Hamilton Depression Rating Scale - Seasonal Affective Disorder Version (SIGH-SAD). Revised ed. New York, NY: New York State Psychiatric Institute; 1994.

50. Rohan KJ, Rough JN, Evans M, et al. A protocol for the Hamilton Rating Scale for Depression: item scoring rules, rater training, and outcome accuracy with data on its application in a clinical trial. JAffect Disord. 2016;200:111-118.

51. Williams JBW, Terman M. Structured Interview Guide for the Hamilton Depression Rating Scale with Atypical Depression Supplement (SIGH$A D S)$. New York, NY: New York State Psychiatric Institute; 2003. 
52. First MB, Spitzer RI, Gibbon M, Williams JBW. Structured Clinical Interview for DSM-IV Axis-I Disorders- Patient Edition (SCID-P). New York, NY: New York State Psychiatric Institute; 1995.

53. Sheehan DV, Lecrubier Y, Sheehan KH, et al. The Mini-International Neuropsychiatric Interview (M.I.N.I.): the development and validation of a structured diagnostic psychiatric interview for DSM-IV and ICD-10. J Clin Psychiatry. 1998;59(Suppl 20):222-233.

54. Rosenthal NE, Bradt GJ, Wehr TA. Seasonal Pattern Assessment Questionnaire (SPAQ). Bethesda, MD: National Institute of Mental Health; 1984.

55. Hardin TA, Wehr TA, Brewerton T, et al. Evaluation of seasonality in six clinical populations and two normal populations. $J$ Psychiatr Research. 1991;25:75-81.

56. Terman M. On the question of mechanism in phototherapy for seasonal affective disorder: considerations of clinical efficacy and epidemiology. J Biol Rhythms. 1988;3:15:5-172.

57. Magnusson A. Validation of the Seasonal Pattern Assessment Questionnaire (SPAQ). J Affect Disord. 1996;40:121-129.

58. Mersch PP, Vastenburg NC, Meesters Y, et al. The reliability and validity of the Seasonal Pattern Assessment Questionnaire: a comparison between patient groups. J Affect Disord. 2004;80:209-219.

59. Terman M, Williams JBW, White TM. Assessment instruments. In: Partonen T, Pandi-Perumal SR, editors. Seasonal Affective Disorder. Practice and Research. 2nd ed. New York, NY: Oxford University Press; 2010:255-264.

60. Meesters Y, Winthorst WH, Duijzer WB, Hommes V. The effects of low-intensity narrow-band blue-light treatment compared to bright white-light treatment in sub-syndromal seasonal affective disorder. BMC Psychiatry. 2016;16:27.

61. Thompson C, Cowan A. The seasonal health questionnaire: a preliminary validation of a new instrument to screen for seasonal affective disorder. J Affect Disord. 2001;64:89-98.

62. Young MA, Hutman P, Enggasser JL, Meesters Y. Assessing usual seasonal depression symptoms: The Seasonality Assessment Form. J Psychopathol Behav Assess. 2015;37:112-121.

63. Thompson C, Thompson S, Smith R. Prevalence of seasonal affective disorder in primary care; a comparison of the seasonal health questionnaire and the seasonam pattern assessmet questionnaire. $J$ Affect Disord. 2004;78:219-226.

64. Pjerk E, Baldinger-Melich P, Spies M, Papageorgiou K, Kasper S, Winkler D. Epidemiology and socioeconomic impact of seasonal affective disorder in Austria. Eur Psychiatry. 2016;32:28-33.

65. Lewy AJ, Kern HE, Rosenthal NE, Wehr TA. Bright artificial light treatment of a manic-depressive patient with a seasonal mood cycle. Am J Psychiatry. 1982;139:1496-1498.

66. Terman M, Terman JS, Quitkin FM, McGrath PJ, Stewart JW, Rafferty B. Light therapy for seasonal affective disorder: a review of efficacy. Neuropsychopharmacology. 1989;2:1-22.

67. Terman M, Terman JS. Light therapy for seasonal and nonseasonal depression: efficacy, protocol, safety, and side effects. CNS Spectr. 2005; 10:647-663.

68. Golden RN, Gaynes BN, Ekstrom RD, et al. The efficacy of light treatment in the treatment of mood disorders: a review and meta-analysis of the evidence. Am J Psychiatry. 2005;162:656-662.

69. Westrin A, Lam RW. Seasonal affective disorder: a clinical update. Ann Clin Psychiatry. 2007;19:239-246.

70. Pail G, Huf W, Pjerk E, et al. Bright-light therapy in the treatment of mood disorders. Neuropsychobiology. 2011;64:152-162.

71. Rosenthal NE, Carpenter CJ, James SP, et al. Seasonal affective disorder in children and adolescents. Am J Psychiatry. 1986;143:356-358.

72. Sonis WA, Yellin AM, Garfinkel BD, Hoberman HH. The antidepressant effect of light in seasonal affective disorder of childhood and adolescence. Psychopharmacol Bull. 1987;23:360-363.

73. Meesters Y, Lambers PA. Light therapy in patient with seasonal fatigue. Lancet. 1990;336:745.

74. Swedo SE, Allen AJ, Glod CA, et al. A controlled trial of light therapy for treatment of pediatric seasonal affective disorder. JAm Acad Child Adolesc Psychiatry. 1997;36:816-821.
75. Lam RW, Tam EW. A clinicians guide to using light therapy. New York: Cambridge University Press; 2009.

76. Labbate LA, Lafer B, Thibault A, Rosenbaum JF, Sachs GS. Influence of phototherapy duration for seasonal affective disorder: outcome at one vs two weeks. Biol Psychiatry. 1995;38:747-750.

77. Meesters Y. The timing of light therapy and response assessment in winter depression. Acta Neuropsychiatr. 1995;7:61-63.

78. Levitt, AJ, Levitan R. Length of light treatment trial: does it influence outcome. Chronobiol Int. 2003;20:1213-1214.

79. Knapen SE, Van de Werken M, Gordijn MC, Meesters Y. The duration of light treatment and therapy outcome in seasonal affective disorder. J Affect Disord. 2014;166:343-346.

80. Provencio I, Rodriguez IR, Jiang G, Hayes WP, Moreira EF, Rollag MD. A novel human opsin in the inner retina. J. Neurisci. 2000;15: 600-605.

81. Berson DM, Dunn FA, Takao M. Phototransduction by retinal ganglion cells that set the circadian clock. Science. 2002;295:1070-1073.

82. Hattar S, Liao HW, Takao M, Berson DM, Yau KW. Melanopsincontaining retinal ganglion cells: architecture, projections, and intrinsic photosensitivity. Science. 2002;295:1065-1070.

83. Dacey DM, Liao HM, Peterson BB, et al. Melanopsin-expressing ganglion cells in primate retina signal colour and irradiance and project to the LCN. Nature. 2005;433:749-754.

84. Lucas RJ, Peirson SN, Berson DM, et al. Measuring and using light in the melanopsin age. Trends Neurosci. 2014;37:1-9.

85. Lockley SW, Brainard GC, Czeisker CA. High sensitivity of the humancircadian melatonin rhythm to resetting by short wavelength light. J Clin Endocrinol Metab 2003;88:4502-4505.

86. Gordijn MC, 't Mannetje D, Meesters Y. The effects of blue-enriched light treatment compared to standard light treatment in seasonal affective disorder. J Affect Disord. 2012;136:72-80.

87. Glickman G, Byrne B, Pineda C, Hauck W, Brainard GW. Light therapy for seasonal affective disorder with blue narrow-band light-emitting diodes (LEDs). Biol Psychiatry. 2006;59:502-507.

88. Strong RE, Marchant BK, Reimherr FW, Williams E, Soni P, Mestas R. Narrow-band blue light treatment of seasonal affective disorders in adults and the influence of additional nonseasonal symptoms. Depress Anxiety. 2009;26:273-278.

89. Anderson JL, Glod CA, Dai L, Lockley SW. Lux vs wavelength in light treatment of seasonal affective disorder. Acta Psychiatr Scand. 2009;120:203-212.

90. Meesters Y, Duijzer WH. The effects of low intensity monochromatic blue light treatment compared to standard light treatment. Soc Light Treat Biol Rhythms. 2011; Abstract 23:52.

91. Anderson JL, St Hilaire MA, Auger RR, et al. Are short (blue) wavelengths necessary for light treatment of seasonal affective disorder? Chronobiol Int. Epub August 5, 2016.

92. Meesters Y, Beersma DG, Bouhuys AL, Van den Hoofdakker RH. Prophylactic treatment of seasonal affective disorder (SAD) by using light visors: bright white or infrared light? Biol Psychiatry. 1999;46:239-246.

93. Danilenko KV, Ivanova IA. Dawn simulation vs bright light in seasonal affective disorder: treatment effects and subjective preference. JAffect Disord. 2015;180:87-89.

94. Terman M, Schlager D, Fairhurst S, Perlman B. Dawn and dusk simulation as a therapeutic intervention. Biol Psychiatry. 1989;25:966-970.

95. Meesters Y. Dawn simulation as maintenance treatment in a 9-year old SAD patient. JAm Acad Child Adolesc Psychiatry. 1989;37:986-988.

96. Leppämäki S, Meesters Y, Haukka J, Lönnqvist J, Partonen T. Effect of simulated dawn on quality of sleep - a community-based trial. $B M C$ Psychiatry. 2003;3:14.

97. Giménez MC, Hessels M, Van de Werken M, De Vries B, Beersma DG, Gordijn MC. Effects of artificial dawn on subjective ratings of sleep inertia and dim light melatonin onset. Chronobiol Int. 2010;27(6):1219-1241.

98. Avery D, Bolte MA, Millet M. Bright dawn simulation compared with bright morning light in the treatment of winter depression. Acta Psychiatr Scand. 1992;85:430-434. 
99. Lingjærde O, Føreland AR, Dankertsen J. Dawn simulation vds. Lightbox treatment in winter depression: a comparative study. Acta Psychiatr Scand. 1998;98:73-80.

100. Avery DH, Eder DN, Bolte MA, et al. Dawn simulation and bright light in the treatment of SAD: a controlled study. Biol Psychiatry. 2001;50:205-216.

101. Levitt AJ, Joffe RT, Moul DE, et al. Side effects of light therapy in seasonal affective disorder. Am J Psychiatry. 1993;150:650-652.

102. Meesters Y, Letsch MC. The dark side of light treatment for seasonal affective disorder. Int J Risk Saf Med. 1998;11:115-120.

103. Remé CE, Rol P, Grotmann K, Kaase H, Terman M. Bright light therapy in focus: lamp emission spectra and ocular safety. Technol Health Care. 1996;4:403-413.

104. Wielgus AR, Roberts JE. Retinal photodamage by endogenous and xenobiotic agents. Photochem Photobiol. 2012;88:1320-1345.

105. Lam RW, Gorman CP, Michalon M, et al. Multicenter, placebocontrolled study of fluoxetine in seasonal affective disorder. $\mathrm{Am} \mathrm{J}$ Psychiatry. 1995;152:1765-1770.

106. Ruhrmann S, Kasper S, Hawellek B, et al. Effects of fluoxetine versus bright light in the treatment of seasonal affective disorder. Psychol Med. 1998;28:923-933.

107. Moscovitch A, Blashko CA, Eagles JM, et al. A placebo-controlled study of sertraline in the treatment of outpatients with seasonal affective disorder. Psychopharmacology. 2004;171:390-397.

108. Lam RW, Levitt AJ, Levitan RD, et al. The Can-SAD study: a randomized controlled trial of the effectiveness of light therapy and fluoxetine in patients with winter seasonal affective disorder. Am J Psychiatry. 2006;163:805-812.

109. Gaynes BN, Kaminski A, Gartlehner G. Second-generation antidepressants for seasonal affective disorder. Cochrane Database Syst Rev. 2011;(12): CD008591.

110. Yildiz M, Batmaz S, Songur E, Oral ET. State of the art psychopharmacological options in seasonal affective disorder. Psychiatria Danubina. 2016;28:25-29.

111. Pjerk E, Winkler D, Konstantinidis A, Willeit M, Praschak-Rieder N, Kasper S. Agomelatine in the treatment of seasonal affective disorder. Psychopharmacology. 2007;190:575-579.

112. Partonen T, Lönnqvist J. Moclobemide and fluoxetine in treatment of seasonal affective disorder. J Affect Disord. 1996;41:93-99.

113. Martiny K, Lunde M, Simonsen C, et al. Relapse prevention by citalopram in SAD patients responding to 1 week of light therapy. A placebo-controlled study. Acta Psychiatr Scand. 2004;109:230-234.

114. Niemegeers P, Dumont GJ, Patteet L, Neels H, Sabbe BG. Bupropion for the treatment of seasonal affective disorder. Expert Opin Drug Metab Toxicol. 2013;9:1229-1240.

115. Golden A-M, Dalgleish T, Spinks H. Dysfunctional attitudes in seasonal affective disorder. Behav Res Ther. 2006;44:1159-1164.

116. Rohan KJ, Roecklein KA, Tierney Lindsey K, et al. A randomized controlled trial of cognitive-behavioral therapy, light therapy, and their combination for seasonal affective disorder. Consult Clin Psychol. 2007;75:489-500.

117. Rohan KJ, Mahon JN, Evans M, et al. Randomized trial of cognitivebehavioral therapy versus light therapy for seasonal affective disorder: acute outcomes. Am J Psychiatry. 2015;172:862-869.

118. Sitnikov L, Rohan KJ, Evan M, Mahon JN, Nillni YI. Cognitive predictors and moderators of winter depression treatment outcomes in cognitive-behavioral therapy vs light therapy. Behav Res Ther. 2013;51:872-881.

119. Martinez B, Kasper S, Ruhrmann S, Moller HJ. Hypericum in the treatment of seasonal affective disorders. J Geriatr Psychiatry Neurol. 1994; 7:S29-S33.

120. Wheatley D. Hypericum in seasonal affective disorder (SAD). Curr Med Res Opin. 1999;15:31-37.

121. Sarris J, Kavanagh D. Kava and St. John's Wort: current evidence for use in mood and anxiety disorders. J Altern Complement Med. 2009; $15: 827-836$.
122. Lingjærde O, Føreland AR, Magnusson A. Can winter depression be prevented by Ginko biloba extract? A placebo-controlled trial. Acta Psychiatr Scand. 1999;100:62-66.

123. Levitt AJ, Brown GM, Kennedy SH, Stern K. Tryptophan treatment and melatonin response in patients with seasonal affective disorder. J Clin Psychopharmacol. 1991;11:74-75.

124. Ghadirian AM, Murphy BE, Gendron MJ. Efficacy of light versus tryptophan therapy in seasonal affective disorder. $J$ Affect Disord. 1998;50:23-27.

125. Lam RW, Levitan RD, Tam EM, Yathan LN, Lamoureux S, Zis AP. L-tryptophan augmentation of light therapy in patients with seasonal affective disorder. Can J Psychiatry. 1997;42:303-306.

126. Pinchasov BB, Shurgaja AM, Grischin OV, Putilov AA. Mood and energy regulation in seasonal and non-seasonal depression before and after midday treatment with physical exercise or bright light. Psychiatry Res. 2000;94:29-42.

127. Leppämäki S, Partonen T, Lönnqvist J. Bright-light exposure combined with physical exercise elevates mood. J Affect Disord. 2002;72:139-144.

128. Meesters Y, Jansen JH, Beersma DG, Bouhuys AL, Van den Hoofdakker RH. Early light treatment can prevent an emerging winter depression from developing into a full-blown depression. J Affect Disord. 1993;29:41-47.

129. Terman JS, Terman M, Amira L. One week treatment of winter depression near its onset: the time course of relapse. Depress Anxiety. 1994;2: 20-31.

130. Meesters Y, Jansen JH, Beersma DG, Bouhuys AL, Van den Hoofdakker RH. An attempt to prevent winter depression by light exposure at the end of September. Biol Psychiatry. 1994;35:284-286.

131. Partonen T, Lonqvist J. Prevention of winter seasonal affective disorder by bright-light treatment. Psychol Med. 1996;26:1075-1080.

132. Nussbaummer B, Kaminski-Hartenthaler A, Forneris CA, et al. Light therapy for preventing seasonal affective disorder (Review). Cochrane Database Syst Rev. 2015;(11): CD011269.

133. Modell JG, Rosenthal NE, Harriett AE, et al. Seasonal affective disorder and its prevention by anticipatory treatment with Bupropion XL. Biol Psychiatry. 2005;58:658-667.

134. Gartlehner G, Nussbaumer B, Gaynes BN, et al. Second-generation antidepressants for preventing seasonal affective disorder in adults (Review). Cochrane Database Syst Rev. 2015;(11): CD011268.

135. Kaminski-Hartenthaler A, Nussbaumer B, Forneris CA, et al. Melatonin and agomelatine for preventing seasonal affective disorder. Cochrane Database Syst Rev. 2015;(11): CD011271.

136. Forneris CA, Nussbaumer B, Kaminski-Hartenthaler A, et al. Psychological therapies for preventing seasonal affective disorder (Review). Cochrane Database Syst Rev. 2015;(11): CD011270.

137. Rohan KJ, Meyerhoff J, S-Y Ho, Evans M, Postolache TT. Outcomes one and two winters following cognitive-behavioral therapy or light therapy for seasonal affective disorder. Am J Psychiatry. 2016;173: 244-251.

138. Segal ZV, Williams JM, Teasdale JD. Mindfulness-Based Cognitive Therapy for Depression: A New Approach to Preventing Relapse. New York, NY: Guilford Press; 2002.

139. Fleer J, Schroevers M, Panjer V, Geerts E, Meesters Y. Mindfulnessbased cognitive therapy for seasonal affective disorder: a pilot study. J Affect Disord. 2014;168:205-209.

140. Stuhlmiller CM. Understanding seasonal affective disorder and experiences in Northern Norway. Image J Nurs Sch. 1998;30:151-156.

141. Traffanstedt MK, Metha S, LoBello SG. Major depression with seasonal variation: is it a valid construct? Clin Psychol Sci. Epub January 16, 2016. doi:10.1177/2167702615615867.

142. Winthorst WH, Post WJ, Meesters Y, Penninx BW, Nolen WA. Seasonality in depressive and anxiety symptoms among primary care patients and in patients with depressive and anxiety disorders; results from the Netherlands Study of Depression and Anxiety. BMC Psychiatry. 2011; $11: 198$. 
143. Winthorst WH, Roest AM, Bos EH, et al. Self-attributed seasonality of mood and behavior: a report from the Netherlands study of depression and anxiety. Depress Anxiety. 2014;31:517-523.

144. Martensson B, Pettersson A, Berglund L, Ekselius L. Bright white light therapy in depression: a critical review. J Affect Disord. 2015;182:1-7.

145. Young MA. Integrating psychological and physiological mechanisms of SAD: the dual vulnerability model. Biol Rhythms Bull. 1999;1:4-6.
146. Enggasser JL, Young MA. Cognitive vulnerability to depression in seasonal affective disorder: predicting mood and cognitive symptoms in individuals with seasonal vegetative changes. Cognit Ther Res. 2007;31:3-21.

147. Young MA, Reardon A, Azam O. Rumination and vegetative symptoms: a test of the dual vulnerability model of seasonal depression. Cognit Ther Res. 2008;32:567-557.
Psychology Research and Behavior Management

\section{Publish your work in this journal}

Psychology Research and Behavior Management is an international, peerreviewed, open access journal focusing on the science of psychology and its application in behavior management to develop improved outcomes in the clinical, educational, sports and business arenas. Specific topics covered in the journal include: Neuroscience, memory and decision making; Behavio
Submit your manuscript here: https://www.dovepress.com/psychology-research-and-behavior-management-journal

\section{Dovepress}

modification and management; Clinical applications; Business and sports performance management; Social and developmental studies; Animal studies. The manuscript management system is completely online and includes a very quick and fair peer-review system, which is all easy to use. Visit http://www. dovepress.com/testimonials.php to read real quotes from published authors. 